\title{
Work Engagement ditinjau dari Organizational Climate pada Karyawan
}

\author{
Irene $^{1}$, Yulinda S. Manurung ${ }^{2}$, Mukhaira El Akmal ${ }^{3}$ \\ Fakultas Psikologi Universitas Prima Indonesia ${ }^{1,2,3}$ \\ irenesmbrg@gmail.com ${ }^{1}$, lindayu109@ hotmail.com², \\ mukhairaelakmal@unprimdn.ac.id ${ }^{3}$
}

\begin{abstract}
Abstrak
Penelitian ini bertujuan untuk mengetahui hubungan antara Organizational Climate dengan work engagement. Subjek penelitian yang digunakan dalam penelitian ini karyawan PT Taman Pesona Indo sebanyak 100 orang (72 laki-laki dan 28 perempuan). Pengumpulan data menggunakan skala Organizational Climate dan skala work engagement. Analisis data yang digunakan adalah menggunakan Pearson Product Moment Correlation. Hasil analisis data menunjukkan koefisien korelasi sebesar 0,527 ( $\mathrm{p}<0,05)$ dan menunjukkan terdapat hubungan positif antara Organizational Climate dengan work engagement. Hasil penelitian ini menunjukkan bahwa sumbangan yang diberikan Organizational Climate terhadap work engagement adalah sebesar 27,8 persen, hal ini menunjukkan adanya hubungan yang sangat signifikan antara variabel organizational climate dengan work engagement pada karyawan.
\end{abstract}

Kata kunci: Karyawan, Organizational Climate, Work Engagement.

\begin{abstract}
This study aims to determine the relationship between Organizational Climate with work engagement. The research subjects used in this study were 100 employees of PT Taman Pesona Indo (72 men and 28 women). Data collection uses the Organizational Climate scale and works engagement scale. Analysis of the data used was used Pearson Product Moment Correlation. The results of data analysis showed a correlation coefficient of 0.527 (p $<0.05)$ and showed a positive relationship between Organizational Climate and work engagement. The results of this study indicate that the contribution made by Organizational Climate to work engagement was 27.8 percent, this shows that there was a very significant relationship between organizational climate variables with work engagement on employees.
\end{abstract}

Keywords: Employees, Organizational Climate, Work Engagement.

\section{PENDAHULUAN}

Sumber daya manusia atau di singkat SDM merupakan faktor penting yang dapat mempengaruhi efektivitas perusahaan dibanding dengan sumber daya yang lain. Seberapa baik sumber daya manusia dikelola akan menentukan kesuksesan perusahaan dimasa mendatang (Purnaya, 2016). Karyawan merupakan sumber daya yang dibutuhkan oleh perusahaan untuk bertindak sesuai dengan tujuan organisasi, fleksibel, inovatif, mau berkontribusi, dan mau bekerja di luar tugas-tugas mereka secara formal, sehingga tujuan perusahaan bisa tercapai dengan maksimal. Hal ini juga dijelaskan oleh Caldwell, Truong, Linh, dan Tuan (2011), menyatakan bahwa dalam sebuah organisasi, sumber daya manusia merupakan salah satu sumber daya yang memegang peranan penting dalam keberhasilan pencapaian tujuan organisasi. Organisasi tidak membutuhkan kekuatan pekerja yang sekedar "sehat" tetapi kekuatan pekerja yang termotivasi adalah engaged (Schaufeli, Leiter \& Taris, 2011). 
Work engagement berati kondisi pikiran yang positif, memuaskan, dan berhubungan dengan pekerjaan yang dicirikan oleh kekuatan, dedikasi dan penyerapan. Dedikasi mengacu pada keterlibatan yang kuat dalam pekerjaan seseorang dan mengalami rasa signifikansi, antusiasme, dan tantangan. dengan tingkat semangat yang tinggi dan identifikasi yang kuat dengan karya seseorang (Bakker \& Michael, 2010).

Menurut Schaufeli, Salanova, Bakker, dan Alezrom (2002), work engagement diartikan sebagai suatu pikiran yang positif terkait dengan pekerjaan dan pemenuhan diri. Pada karyawan yang sudah menikah, work engagement merefleksikan tingginya semangat dan dedikasi, serta absorbsi. Menurut Susilo dan Prahara (2019), organisasi modern mengharapkan para karyawannya untuk dapat bersikap proaktif dan penuh inisiatif, dan mengambil tanggung jawab sebagai bagian dari perkembangan profesional mereka dan komitmen terhadap standar kinerja yang tinggi. Karyawan yang terikat adalah karyawan yang sangat energik dan menggunakan pengaruh yang positif terhadap peristiwa yang mempengaruhi hidup mereka.

Work engagement dapat dihubungkan Organizational Climate (Kose 2016). Pendapat tersebut juga didukung oleh Sarlak (2013) yang menyatakan bahwa Organizational Climate dapat memengaruhi tingkat work engagement seseorang. Semakin tinggi Organizational Climate yang dimiliki seseorang, maka tingkat work engagement akan semakin tinggi. Sehingga, Organizational Climate berkorelasi positif dengan work engagement, yang berarti rendahnya Organizational Climate juga dapat berdampak pada rendahnya work engagement seseorang.

Menurut Wirawan (2008), organizational climate merupakan penilaian anggota organisasi baik secara individual atau kelompok, dengan catatan bahwa individu melakukan penilaian selama terhubung dengan lingkungan internal organisasi secara rutin sehingga dapat mempengaruhi individu dalam berorganisasi. Hal yang sama di sampaikan oleh Albrecht (2011) bahwa organizational climate berakar dari studi tentang persepsi yang dimiliki individu dari berbagai aspek lingkungan dalam organisasi. Dengan demikian pengkajian organizational climate dapat dilakukan dengan menggali data dari persepsi individu yang ada dalam organisasi.

Richa, Santosh, dan Mukesh (2014), mendefinisikan organizational climate sebagai ringkasan atau persepsi global yang dimiliki oleh anggota mengenai organisasinya, individu akan memahami organisasi sesuai dengan situasi dan informasi yang tersedia. Sarlak (2013) berpendapat bahwa Iklim diciptakan oleh organisasi (seperti manager, administrator) dan struktur organisasi (seperti strategi, praktik), dan dilaksanakan sebagai persepsi karyawan. Iklim organisasi yang kondusif memiliki keterikatan kerja karyawan, penilaian terhadap iklim organisasi yang positif dapat meningkatkan dukungan organisasi seperti dukungan pengawas, tantangan dan otonomi kerja, pengakuan dan penghargaan, dan persepsi keadilan. Jadi iklim organisasi sejalan dengan adanya dukungan organisasi sehingga tercipta keterikatan kerja dalam diri karyawan.

Menurut Xanthopoulou, Bakker, Demerouti dan Schaufeli (2007), ada beberapa sumber daya yang berperan membentuk work engagement meliputi kontrol pekerjaan, dukungan atasan, informasi, apresiasi, inovasi dan iklim organisasi. Xanthopoulou dkk (2007) juga menyebutkan di antara sumber tersebut, Iklim organisasi menjadi sesuatu yang penting dalam mempengaruhi work engagement, sebabi Iklim organisasi dianggap sebagai salah satu penguat individu ketika dihadapkan pada situasi lingkungan kerja yang penuh tekanan. Berdasarkan 
uraian sebelumnya, maka peneliti tertarik untuk meneliti hubungan antara Organizational Climate dengan work engagement pada karyawan PT. Taman Pesona Indo.

\section{METODE}

Penelitian ini dilakukan dengan metode kuantitatif (Siswanto, Susila \& Suyanto 2017). Subjek dalam penelitian ini sebanyak 100 orang karyawan PT Taman Pesona Indo. Teknik pengambilan subjek menggunakan total sampling. Data dikumpulkan dengan menggunakan 2 skala, yaitu work engagement dan skala Organizational Climate. Skala work engagement yang digunakan dalam penelitian ini di susun berdasarkan aspek yang dikemukakan oleh Schaufeli, Salanova, Bakker dan Alez-rom (2002) berdasarkan aspek-aspek diantaranya yaitu vigor, dedication, dan absorption dengan nilai reliabilitas $\alpha$ sebesar 0,949 dengan nilai $r$ bergerak dari 0,340 sampai 0,811. Skala ini disusun dengan model skala likert yang berjumlah 41 aitem. Masing-masing aitem disediakan 5 kategori pilihan jawaban, yaitu 1 (Sangat Sesuai), sampai dengan 5 (Sangat Tidak Sesuai).

Sedangkan organizational climate yang digunakan dalam penelitian disusun berdasarkan aspek yang dikemukakan oleh Wirawan (2008) organizational climate memiliki aspek-aspek diantaranya yaitu struktur, standar-standar, tanggung jawab, pengharapan, dukungan, komitmen. Skala ini disusun dengan model skala likert yang berjumlah 43 aitem. Masingmasing aitem disediakan 5 kategori pilihan jawaban, yaitu 1 (Sangat Sesuai), sampai dengan 5 (Sangat Tidak Sesuai). Koefisien korelasi bergerak dari (r) 0,364 sampai 0,848. Sedangkan Koefisien reliabilitas skala organizational climate adalah sebesar 0,956.

\section{HASIL}

Tabel 1.

Karakteristik Subjek

\begin{tabular}{lcc} 
Gender & Jumlah & Persentase $\mathbf{( \% )}$ \\
\hline Laki-laki & 72 & 72,0 \\
\hline Perempuan & 28 & 28,0 \\
\hline Total & 100 & 100
\end{tabular}

Tabel 2.

Data Deskriptif Work engagement dan Organizational Climate

\begin{tabular}{lll}
\hline & Work engagement & Organizational Climate \\
\hline Skor Minimum & 88 & 97 \\
\hline Skor Maksimum & 149 & 150 \\
\hline Skor Rata-rata & 122,95 & 129,8 \\
\hline Standar Deviasi & 10,8 & 7,87 \\
\hline Kategori Rendah (Persentase) & 0 & 0 \\
\hline Kategori Sedang (Persentase) & $58(58 \%)$ & $51(51 \%)$ \\
\hline Kategori Tinggi (Persentase) & $42(42 \%)$ & $49(49 \%)$ \\
\hline
\end{tabular}


Berdasarkan data pada tabel 1, untuk variabel work engagement, terdapat 0 subjek ( 0 persen) yang memiliki work engagement rendah, terdapat 58 subjek (58 persen) yang memiliki work engagement sedang, dan terdapat 42 subjek (42 persen) yang memiliki work engagement tinggi. Berdasarkan penjelasan di atas maka dapat disimpulkan bahwa rata-rata subjek penelitian memiliki work engagement tinggi. Dari skala work engagement diperoleh mean empirik sebesar 122,95 dengan standar deviasi 10,8. Data menunjukkan mean empirik > mean hipotetik yaitu 122,95 > 102,5 maka dapat disimpulkan bahwa work engagement pada subjek penelitian lebih tinggi daripada populasi pada umumnya.

Selanjutnya, untuk variabel self disclosure, terdapat 0 subjek (0 persen) yang memiliki Organizational Climate rendah, terdapat 51 subjek (51 persen) yang memiliki Organizational Climate sedang, dan terdapat 49 subjek (49 persen) yang memiliki Organizational Climate tinggi. Berdasarkan penjelasan di atas maka dapat disimpulkan bahwa rata-rata subjek penelitian memiliki Organizational Climate sedang. Dari skala Organizational diperoleh mean empirik sebesar 129,8 dengan standar deviasi 7,87. Diketahui bahwa mean empirik > mean hipotetik yaitu 129,8 > 107,5 maka dapat disimpulkan bahwa Organizational Climate pada subjek penelitian lebih tinggi daripada populasi pada umumnya.

\section{Uji Asumsi}

Berdasarkan hasil uji normalitas Kolmogorov-smirnov work engagement memiliki nilai signifikansi sebesar 0.122 (p>0.05), sedang Organizational Climate sebesar 0.227 ( $\mathrm{p}>0.05$ ), yang berarti bahwa data pada kedua variabel memiliki sebaran data terdistribusi normal. Berdasarkan hasil pengujian linearitas, dapat dilihat nilai sig sebesar 0.000 yang mana $\mathrm{p}<0.05$, sehingga dapat disimpulkan bahwa kedua variabel memiliki hubungan linear dan memenuhi syarat untuk dilakukan analisis Pearson Product Moment Correlation.

\section{Uji Hipotesis}

Tabel 3.

Hasil Uji Hipotesis

\begin{tabular}{ccccc}
\hline Variabel & Pearson Product Moment & $R$ Square & sig & Keterangan \\
\hline WE terhadap OC & 0,527 & 0,278 & 0,000 & Signifikan \\
\hline
\end{tabular}

Berdasarkan hasil uji hipotesis dengan teknik Pearson Product Moment Correlation pada tabel 2 ditemukan bahwa terdapat hubungan positif yang kuat dan signifikan antara work engagement dengan Organizational Climate $(\mathrm{r}=0,527, \mathrm{p}=0.000<0,005)$. Hal ini menunjukkan bahwa adanya hubungan yang positif dan signifikan antara work engagement dengan Organizational Climate sehingga dikategorikan hubungan yang kuat (Priyatno, 2011). Dari hasil perhitungan tersebut, maka hipotesis yang diajukan dalam penelitian ini menunjukkan terdapat hubungan positif antara work engagement dengan Organizational Climate pada karyawan PT. Taman Pesona Indo dapat diterima. Dalam penelitian ini juga diperoleh koefisien determinasi $\left(\mathrm{R}^{2}\right)$ sebesar 0.278. Berdasarkan hasil tersebut, dapat disimpulkan bahwa sumbangan 27,8 \% work engagement terhadap Organizational Climate. 


\section{PEMBAHASAN}

Hasil penelitian ini menunjukkan adanya hubungan antara Organizational Climate dengan work engagement pada karyawan PT. Taman Pesona Indo. Hal ini sesuai dengan ciri-ciri yang diutarakan oleh Richa, Santosh dan Mukesh (2014) dengan peningkatan nilai aspek-aspek organizational climate yang digunakan seperti otonomi, kerjasama, penghargaan, keseimbangan kehidupan kerja, organisasi kerja, partisipasi, relasi, inovasi dan kelekatan terhadap pekerjaan akan menunjukkan work engagement seperti dedikasi, antusiasme pada diri karyawan tersebut.

Hubungan yang positif ini menjelaskan semakin baik Organizational Climate pada karyawan PT. Taman Pesona Indo maka semakin tinggi work engagement yang dirasakan. Sehingga, hipotesis yang diajukan dalam penelitian ini diterima. Temuan penelitian ini sesuai dengan pernyataan yang dipaparkan oleh Yongxing, Hongfei, Baoguo dan Lei (2017), mengatakan bahwa semakin baik iklim organisasi (Organizational Climate) dalam perusahaan tersebut maka semakin tinggi rasa keterikatan kerja karyawan, dan sebaliknya.

Hasil yang senada juga didapatkan pada penelitian yang dilakukan oleh Astika, Nurlintang dan Saptoto (2016), hasil penelitian ini menunjukkan bahwa terdapat hubungan yang positif yang signifikan antara iklim organisasi dengan keterikatan kerja. Hasil tersebut diperkuat oleh salah satu penelitian yang dilakukan oleh Dajani (2015) tentang Investigating the Effect of Organizational Climate on work engagement, ada korelasi hubungan antara iklim organisasi dan work engagement. Penelitian yang dilakukan Alessandro, Carmela dan Maria (2019), iklim organisasi sebagai kepribadian sebuah organisasi yang membedakan dengan organisasi lainnya yang mengarah pada persepsi masing-masing anggota dalam memandang organisasi sehingga memiliki keterikatan kerja karyawan.

Hasil penelitian ini menunjukkan bahwa tidak ada karyawan PT. Taman Pesona Indo yang memiliki keterikatan kerja yang sedang 58,0\% karyawan memiliki katerikatan kerja yang tinggi $42 \%$ karyawan. Secara keseluruhan dapat dilihat bahwa mayoritas karyawan PT. Taman Pesona Indo memiliki keterikatan kerja yang tinggi. Karyawan dengan keterikatan kerja yang tinggi dapat memenuhi dimensi keterikatan kerja, meliputi vigor, dedication dan absorption. Bakker dan Leiter (2015) menyebutkan individu dengan keterikatan kerja yang baik mempu memperlihatkan keadaan psikologi yang positif untuk pemenuhan kerja dan di karakteristikan dengan vigor, dedication, dan absorption. Vigor dalam diri karyawan gambarkan melalui tingginya tingkat energi dan ketahanan mental saat bekerja, selain itu juga dicirikan dengan ketekunan dan kemauan untuk berusaha dalam menyelesaikan pekerjaan maupun kesulitan pada lingkungan pekerjaan. Dedication tidak hanya sebatas pada keterlibatan dalam penyelesaian masalah namun juga berkaitan dengan afeksi dan emosi, dengan mengalami perasaan yang bermakna, antusiasme, inspirasi, kebanggaan, dan tantangan. Sementara Absorption karyawan akan dihadapkan pada perasaan waktu cepat berlalu dan kesulitan untuk melepaskan diri dari pekerjaan, di sisi lain ditandai dengan konsentrasi penuh namun demikian tetap merasa senang melakukan pekerjaannya.

Kuntari (2017) menyatakan bahwa keterlibatan secara fisik, emosional dan kognitif pada pekerjaan berpeluang untuk meningkatkan keberhasilan dalam menjalankan pekerjaan. Oleh karena itu, untuk menilai iklim organisasi yang kondusif bagi keterikatan kerja karyawan, penilaian terhadap iklim organisasi yang positif dapat meningkatkan dukungan organisasi seperti dukungan pengawas, tantangan dan otonomi kerja, pengakuan dan penghargaan, dan 
persepsi keadilan. Jadi iklim organisasi sejalan dengan adanya dukungan organisasi sehingga tercipta keterikatan kerja dalam diri karyawan.

Secara menyeluruh hasil dari penelitian ini didapat bahwa aspek-aspek struktur, standarstandar, dukungan, dan komitmen memiliki hubungan antara work engagement karyawan PT. Taman Pesona Indo. Semakin tinggi skor aspek-aspek struktur, standar-standar, dukungan, dan komitmen maka semakin tinggi pula skor work engagement. Sedangkan tanggung jawab dan pengharapan pada penelitian ini didapatkan hasil bahwa tidak memiliki hubungan terhadap work engagement. Beberapa hasil temuan dalam penelitian organizational climate masih ada inkonsistensi dengan temuan penelitian ini, sehingga bisa dijadikan masukkan untuk penelitian selanjutnya. Hasil penelitian ini diharapkan mempunyai implikasi sebagai bahan pertimbangan agar perusahaan mengetahui hal-hal apa saja yang harus diperhatikan, salah satunya adalah bagaimana perusahaan mengubah sistem kerja untuk meningkatkan produktivitas perusahaan agar karyawan memiliki rasa tanggung jawab yang tinggi terhadap perusahan, sehingga tercapai tujuan dari perusahaan tersebut (Askari, 2017).

\section{KESIMPULAN}

Berdasarkan hasil penelitian yang telah diperoleh, dapat dipahami bahwa hipotesis yang diajukan dalam penelitian ini dapat diterima, dimana terdapat hubungan positif dan signifikan antara Organizational Climate dengan work engagement pada karyawan PT. Taman Pesona Indo. Hasil penelitian ini diharapkan dapat menjadi masukan bagi perusahaan, sebaiknya perusahaan senantiasa memberikan lebih banyak ruang untuk karyawan bekerja sama baik dengan rekan kerja maupun dengan atasan, agar iklim yang kondusif akan terus berlangsung. Perusahaan tetap menjalankan model kepemimpinan yang sesuai dengan apa yang diharapkan oleh para karyawan, seperti yang telah dilakukan selama ini. Serta perusahaan mampu meningkatkan motivasi karyawan agar kinerja karyawan dapat meningkat.

Peneliti selanjutnya diharapkan dapat meneliti faktor-faktor lain, seperti karakteristik tugas, kepribadian, manajemen waktu, dan motivasi berprestasi, religiusitas, locus of control, kecerdasan sosial, dukungan keluarga, kepribadian introversi, penggunaan internet, kualitas komunikasi, kebutuhan afiliasi, dan presentasi diri yang dapat berpengaruh terhadap work engagement.

\section{DAFTAR PUSTAKA}

Albrecht (2011) "Professional development of early career teachers: A pedagogical focus on cooperative learning". Issues in Educational Research, Vol.21, No. 2, 2011, pp: 109 129, http://www.proquest.umi.com diakses pada 30 Maret 2018.

Alessandro Ancarani, Carmela Di Mauro \& Maria Daniela Giammanco (2019) Linking Organizational Climate to Work Engagement: A Study in the Healthcare Sector, International Journal of Public Administration, 42:7, 547557, http://doi: 10.1080/01900692.2018.1491595

Askari, R., Zareh, T., Tayefi, E., Sepaseh, F., \& Bahrami, M.A. (2017). Investigating the relationship between organizational climate and the personality characteristics of employees. Bali Medical Journal (Bali Med J) 2017, Volume 6, Number 1: 1-5 PISSN.2089-1180, E-ISSN.2302-2914. http://doi:10.15562/bmj.v6i1.387 
Astika L, Nurlintang F, \& Saptoto R. (2016). Peran Resiliensi dan Iklim Organisasi terhadap Work Engagement." Jurnal Psikologi UGM, vol. 2, no. 1, 2016, http://doi:10.22146/gamajop.31868

Bakker, A. B. \& Michael, P. L. (2010). Work engagement a handbook of essensial theory and research. New York: Psychology Press.

Bakker, A. B., \& Leiter, M. P. (2015). The Peak Performing Organizational. New York. Oxford University Press.

Caldwell, C., Truong, D. X., Linh, P. T., \& Tuan, A. (2011). Strategic human resource management as ethical stewardship. Journal of Business Ethics, 98(1), 171-182. https://doi.org/10.1007/s10551-010- 0541-y

Dajani, M. A. Z. (2015). The Impact of Employee Engagement on Job Performance and Organisational Commitment in the Egyptian Banking Sector. Journal of Business and Management Science, 3(5), 138-147. http://doi.org/10.12691/jbms-3-5-1

Fraenkel, Jack. R., and Norman E. Wallen. 2012. How to Design and Evaluate Research in Education 8th Edition. Boston: McGraw-Hill Higher Education.

Kose, A. (2016). The Relationship between Work Engagement Behavior and perceived Organizational Support and Organizational Climate. Journal of Education and Practice, Vol ,7. No 27.

Kuntari, C. M. I. S. R. (2017). Hubungan workfamily enrichment dengan work engagement pada perawat wanita. Jurnal Psikologi Ulayat, 2(1), 407. https://doi.org/10.24854/jpu12015-35

Siswanto, Susila, \& Suyanto. (2017). Metodologi Penelitian Kombinasi Kualitatif Kuantitatif Kedokteran dan Kesehatan. Klaten : Bossscript.

Sugiyono. (2014). Metode Penelitian Pendidikan Pendekatan Kuantitatif Kualitatif dan R\&D. Bandung: Alfabeta

Schaufeli, W. B., Salanova, M., Bakker, A. B., \& Alez-rom, V. G. (2002). The measurement of engagement and burnout: A two sample confirmatory factor. Journal of Happines Studies, 3, 71-92. https://doi.org/10.1023/A:10156309303 26

Schaufeli, W. B., Leiter, M. P., \& Taris, T. W. (2011). Job demands, job resources and their relationship with burnout and engagement: A multi-sample study. Journal of Organizational Behavior, 25(3), 293-315

Susilo, D.F.Z \& Prahara, S.A. (2019). Work-Family Enrichment dan Work Engagement pada Karyawan yang Sudah Menikah. Jurnal Mediapsi, 2019, Vol. 5, No. 2, 108-116. https://doi.org/10.21776/ub.mps.2019.005.02.5

Purnaya, I Gusti Ketut. 2016. Manajemen Sumber Daya Manusia. Yogyakarta: Andi.

Richa Chaudhary, Santosh Rangnekar, \& Mukesh Kumar Barua. (2014). Organizational Climate, Climate Strength and Work Engagement. Procedia-Social and Behavioral Sciences Vol. 133, 15 May 2014, Pages 291-303. https://doi.org/10.1016/j.sbspro.2014.04.195 
Sarlak M.A. (2013). The New Faces Of Organizations in The $21^{\text {th }}$ Century. Canada : Naisti Publishers.

Wirawan. 2008. Budaya dan Iklim Organisasi. Jakarta. Salemba Empat.

Xanthopoulou, D., Bakker, A. B., Demerouti, E., \& Schaufeli, W. B. (2007). The role of personal resources in the job demands-resources model. International Journal of Stress Management, 14(2), 121-141. https://doi.org/10.1037/1072-5245.14.2.121

Yongxing, G., Hongfei, D., Baoguo, X., \& Lei, M. (2017). Work engagement and job performance: the moderating role of perceived organizational support. Anales De Psicología / Annals of Psychology, 33(3), 708-713. https://doi.org/10.6018/analesps.33.3.238571 